\title{
Fieldnotes on some cockroaches at SOAS and in
}

\section{Stavanger, Norway.}

Ingie Hovland (School of Oriental and African Studies, University of London)

This paper explores various aspects of doing 'anthropology of home'. An anthropologist of home does not go 'elsewhere' to produce the experiential shifts that can lead to anthropological knowledge. She experiences shifts at home. In this paper I am interested in exploring precisely these experiential shifts - these 'dislocations'-and how they might be instrumental in producing anthropological insight. I want to suggest that 'dislocation insights', as I call them, can come about not just when crossing geographical distance but also when confronted with familiar categories that suddenly become strange, when confronted with yourself in a new way, or when confronted with the unheimlich - the unhomelike - at home.

\section{Introduction}

This paper is about the anthropology of home. It is about how disconcerting and fascinating it can be to study home, and it is about why studying home is important, in the larger anthropological scheme of things, as one way of producing anthropological knowledge. I would like to introduce the topic through an extract from Gupta and Ferguson:

'Ethnography has always contained at least some recognition that
knowledge is inevitably both "about somewhere" and "from
somewhere", and that the knower's location and life experience are
somehow central to the kind of knowledge produced. Yet, through the
anthropological notion of "the field", this sense of location has too often
been elided with locality, and a shift of location has been reduced to the
idea of going "elsewhere" to look at "another society".' (Gupta and
Ferguson 1997: 35)

Location is somehow central to the knowledge produced. Location has been elided with locality. Shifts in location are not necessarily about going elsewhere; shifts in location can also come about at home.

\section{Where will you go on fieldwork?}

Monday 16th December, 2002, SOAS. I bumped into B on the stairs and he remembered that I was doing anthropology: 'When are you going on fieldwork?'-'I don't go until August; to Norway'- 'Right, but when are you going on fieldwork?'This made me feel a bit embarrassed, so I skipped the argument - 'I may be going to Madagascar for about a month some time in 2004. It's still uncertain, though; it will 
depend on my research in Norway.' He ignored the uncertainty. 'Ah, excellent! Madagascar is a brilliant place.'

Later I met up with some of the people from last year in the bar, D asked me about my $\mathrm{PhD}$ and I gave him the usual intro, short version: 'I'm going to look at something called the Norwegian Mission Society, how and why they still exist today when the idea of mission is pretty controversial in Norway.' He looked at me: 'Right... And how did you come up with that topic?' I explained that my parents had in fact been missionaries for the mission society, and before them, my grandparents as well. D still looked puzzled: 'But then why... how... I mean-where will you go-on fieldwork?'-'Well...' I hesitated this time, wishing I could give the name of some exotic anthropological paradise, 'the Norwegian Mission Society is based in Norway, so...' He looked at me in disbelief: 'You're going back home to Norway? No!' He paused; 'Where did the missionaries go?'- 'Well, some of them went to Africa, but I'm not really looking at...' I stopped short; he was delighted: 'Africa! You have to go to Africa!' I mumbled something about maybe going to Madagascar, which seemed to clinch it.

As I wandered through corridors and seminars at SOAS I tried to avoid saying that my field would be in Norway. If possible, I tried to avoid using the word 'field' at all. Suddenly I felt a bit lost in a place that I thought was familiar. I felt out-of-joint with my university and my discipline. These were the first dislocation insights that provoked questions around the categories of home and field for me.

\section{Home}

When field and home coincide, what kind of anthropology do you get? In this paper I call it 'anthropology of home'. Anthropologists of home choose to study groups through which they can study themselves - in the network of friends they have built up over the years (Pink 2000), in the context of the development project for which they have worked as a consultant for over a decade (Mosse 2005), at the boarding school they attended a long time ago (Okely 1996). They are at home in these spaces in different and sometimes difficult ways. But what they have in common is that they turn home into a critical category. These anthropologists use themselves, at home, as 'principal informant'.

Anthropology of home is concerned with the category of home as an experiential plane - a feeling or frame of mind. We long for spaces where we can feel at home, and yet these very spaces are the ones that can hurt us the most. Home is about patterns of self-recognition, but it is also about conflicts and insecurity. Home can be a 'safe' and 'normal' space, but it is also a space where the unheimlich, the un-homelike or uncanny can emerge. The uncanny is terrifying because it comes about in a space that we thought was familiar, and that we are unable to separate ourselves from completely (Freud 1953).

Within anthropology it is easy to slip into a conceptual scheme where 'home' is regarded as the categorical opposite to the 'field'. When examining home-and home becomes the field - this home/field opposition needs to be rethought. This is sometimes challenging because the home/field opposition is one of the ideas that sustains the fieldsite 'hierarchy of purity', as Gupta and Ferguson call it. The purity of fieldsites, they suggest, has traditionally been seen as related to distance: 'one can only encounter difference by going elsewhere, by going to "the field" (Gupta and 
Ferguson 1997: 8). The purity may also have to do with the degree of separation between insider and outsider roles; sometimes the field becomes less pure the less clearly the anthropologist can be categorized as an outsider. Related to this is the degree of separation between the familiar and the strange. The more familiar the field, the less pure the fieldwork. In practice these distinctions are difficult to make; there are connections that erase geographical boundaries today, and the distinctions between 'here' and 'there', familiar and strange, are far murkier than before:

\begin{abstract}
'in a world of infinite interconnections and overlapping contexts, the ethnographic field cannot simply exist, awaiting discovery. It has to be laboriously constructed, prised apart from all the other possibilities for contextualization to which its constituent relationships and connections could also be referred.' (Amit 2000: 6)
\end{abstract}

But although the categories of 'home' and 'field' are difficult to keep clearly separate in practice, they still have a certain appeal in theory - not just for anthropologists who have already gone on fieldwork to faraway places and who have some stake in maintaining the hierarchy of purity. The categories of purity appeal to me as well; categories where you can separate insiders from outsiders, the familiar from the unfamiliar, and home from away. Categories are good to think with. Which I think is why I feel so out of place when my own fieldsite, in these terms, turns out to be impure.

\title{
Mud huts
}

Tuesday 10th June, 2003, SOAS. C and F had their upgrade vivas at the same time as I did. I went down to the bar afterwards to find them; I was in a particularly bad mood, and this was not made any better when I heard that my fellow students had finished an hour earlier than me after what they described as a pleasant conversation. I looked at C: 'You had a pleasant conversation?'-_Yes,' she smiled happily, 'What did you have? And did it last right until now? What on earth did you talk about for so long?'

Our discussion had started off with Dr Y's opening question: 'I see you've put down ten months fieldwork at the mission society in Norway and then maybe one or two months with the missionaries in Madagascar. Now, I was wondering whether you shouldn't reverse that and start off with Madagascar instead - and then maybe stay in Madagascar and do fieldwork there for, say, six, eight, ten months?' The blank horror on my face must have made it clear that I was not expecting this, because Drs $\mathrm{Y}$ and $\mathrm{Z}$ hurried to elaborate: it seemed like I knew the mission society already, they said, they didn't understand why I should immediately go back to something that was so familiar; wouldn't it be better if I went somewhere more unknown, experienced something new? I tried to explain: 'No, that would be a different $\mathrm{PhD}$; for my $\mathrm{PhD}$ I'm not...'-I searched for a reasonable way of describing my concern, but didn't quite succeed-'I'm not that hooked on fieldwork', I mumbled. Stunned silence. Then horrified looks. Of all the unreasonable answers I could have chosen, I realized very quickly that it should not have been this one. Alas, too late.

The inevitable result was a protracted discussion that took up the next hour and a half, circling around the mysterious and indefinable fieldwork ingredient $\mathrm{X}$ that needs to be present for a $\mathrm{PhD}$ to be anthropological. Could I conduct fieldwork by looking once more at a group that I knew, in a setting that I was able to imagine because I had been 
in it before - and in Norway, of all places? After we had repeated our respective views on fieldwork ingredient $\mathrm{X}$ a few more times, and as I was just beginning to regain the ability to speak in complete sentences, Dr Z glanced at his watch. 'Of course,' he asserted, in an attempt to reach a conclusion, 'of course, we all know that fieldwork doesn't have to mean sitting in mud huts.' Relief all around at this observation. I took it to mean that I could do what I had originally wanted to do and still stay within the anthropology department. And at that, it seemed agreed that I could go out to the field of the mission society head office in Stavanger, Norway.

\section{Somewhere strangely familiar}

Wednesday 17th September, 2003, the mission society head office, Stavanger. I finally braved the mission society canteen at lunchtime. I had been delaying the lunchtime introduction sequence for a while, not very keen on walking into a crowded canteen, mostly full of strangers, looking at me. I took a few deep breaths and forced myself to dive in anyway.

Lunch: luckily I met $\mathrm{AK}$ and $\mathrm{E}$ on their way into the canteen, lost them again but met $\mathrm{M}$ (now in job $\mathrm{PH}$ had before). Sat down at her table - shook hands with J and two people I didn't know $(\mathrm{O}$ and $\mathrm{H})$. AK came over and joined us. J said he remembered my grandfather from the time when he was here in Stavanger-and of course he has just sent my mother off to Ethiopia. He explained (to $\mathrm{O}$ ) that he had known my father who had died three years ago - very straightforwardly and warmly, I appreciate it when people can say it and also signal that they care. $\mathrm{H}$ smiled after this whole introduction story and commented: so now we've placed you.

Announcements. AK got me to stand up to say what I'm doing. Sea of faces around me, turned towards me, expectant. Many of the faces recognized my name. 'I'm doing a $\mathrm{PhD}$ in anthropology in London, I'm here for a year of fieldwork, and going to think about how the mission society, as an organization with a fairly controversial aim (a man behind me half stifled a laugh but stopped immediately), namely to convert others to one's own faith, has been made and how the mission society maintains itself and its legitimacy. Both in relation to insiders and to outsiders.' Breath. Faces waiting for what I was going to say next, some faces smiling at me. 'I also feel a certain need to say that I have grown up in the mission society, I feel a certain attachment and (had to swallow) loyalty to the organization, and I feel the need to emphasize that side of the matter too.' The faces burst out in friendly laughter, I smiled, had to wait for the laughter to quiet down. Many faces smiling. Felt good to stand there. 'Especially in relation to you. I hope to speak to many of you during the year.' Sat down again. Afterwards $M$ commented that it sounded very interesting, I smiled, said I was never quite sure how to phrase it here in the canteen, the others around the table smiled too and AK said that was ok, just say it like it is.

Song, Bible reading (don't remember which), song (with line 'when I have thought myself tired unto death then say what you have thought o God' - remembered how much it touched me and meant to me at the last general assembly, 2002), short devotion, song. I made sure I sang along on all the songs, a certain satisfaction/security from knowing that I know them all, felt it gave me some legitimacy. Then end of lunch-I was pleased afterwards. And excited and thoughtful and uncertain, all at the same time; the mission society stirs up many feelings in me. I went for a walk in the cemetery and wondered whether I was angry at the mission 
society and in what way I miss my father, and how those two threads were maybe guiding other things in this research process.

Anthropologists of home face challenges that are not exclusive to them, but which are often exacerbated by their 'strange familiarity' in the group they are studying. They elicit reactions from the group that are different from those that a complete stranger would encounter. It takes a considerable amount of time to work through what the familiar reactions and relationships mean in relation to the research. And then anthropologists of home may feel satisfied and secure in that they already have a place and already 'know the score'. And then, after that, anthropologists of home have to work hard to figure out the unique and often contradictory ways in which they feel at home in this particular group. Most anthropologists have to work through these questions; but for the anthropologist of home there is, perhaps, slightly more at stake in terms of losing or retaining (or having to redefine) the basic security that is tied to having an identity at home. Which brings me back to the cockroaches.

\section{How can things be this way?}

Only a while after having become familiar with the plastic tables and green plants of the mission canteen did I realize that I should have pursued the earlier mud hut question in the viva. Because even though the anthropologist doesn't need mud huts to conduct fieldwork any longer, one does need something; something that is different, something that will challenge you, startle you, make you ask questions, make you receptive to what is going on around you; and for want of a better term to describe this something, I suggest cockroaches. Let me explain.

Although it was never stated explicitly in our anthropological methods classes, I was left with the vague understanding that the more cockroaches you had crawling around in your bed at night, the better fieldwork you would be able to conduct during the day. Undoubtedly, finding oneself in bed with a couple of irretrievable, scuttling cockroaches drives one quickly into that out-of-the-ordinary, despairing space where the question par excellence of modernist sensibility and ethnographic research becomes urgent: 'How can things be this way?' (Des Chene 1997: 66). The discomfort of illness, the strangeness of a foreign place, the loneliness, the inability to communicate fluently: traditional fieldwork is designed to drive students into the state of mind that makes you lose the ground beneath your feet, and, hopefully, makes you susceptible to new impressions and alternative ways of seeing the world. The traditional hardships of fieldwork have the effect of making the anthropologist come to know herself better, and also to enable her to 'go out of herself', to push herself to new understanding.

Against this background, the anthropological scepticism towards anthropology of home is understandable; anthropology of home sounds so easy, so familiar, so close'so comfortable', as Prof $\mathrm{N}$ jokingly remarked to me one day. I want to suggest, however, that the fieldwork process from anxiety to method is no less fraught when the anxiety comes - not necessarily with discomfort from sleeping in a bed full of cockroaches-but instead from the disconcerting experience of facing your own group, a part of yourself, your past and present; memories, good relations, bad relations, loyalties, disappointments; all the implications of being in a group where you feel at home. In fact, the conceptual world of an anthropologist of home is sometimes a veritable cockroach heaven. 


\section{The application from 1842}

Tuesday 23rd September, 2003, the mission society, Stavanger. I have just read through an application sent to the mission school in 1842 from a certain Tobias Udland, reprinted in the mission magazine Norsk Missions-Tidende 1878 (first leaflet). Touching and disturbing. For an instant, cockroaches came scurrying out all over the page and swarmed into my head; the sentences written down by this applicant reminded me of states of mind that were suddenly, unexpectedly, all too familiar. 'I now still remained in the state, I was in, and I was now and then so anxious, that I even cried, as I was working,' he writes. 'I forgot to keep a vigil over myself... no salvation for me anymore...' He knows which language to frame this in, he knows the classical sequencing of a pietistic religious crisis, as he takes me through the twists and turns of doubt, guilt, despair, crisis event; then grace, feeling of freedom, conviction. These are the states of mind that you are expected to go through, within this strand of Christianity, as you are confronted first with your own sinfulness and the possibility of eternal damnation, and then with God's offer of salvation if you believe in his forgiveness. The religious crisis narrated in the old application stays close to the expected schema. But all the while there is an unresolved edge to his sentences. 'That spring was for me as if I had been let out of a prison... but my heart...' He's still depressed as he's writing, I think, then he carries on: 'The toil, I then had, I cannot express, all that mattered to me was to be saved...' Saved from hell.

'Scarily similar', I've scribbled down in my notes from that day. Underlined three times, and then a few quick keywords, in red. How can his words resonate so closely with what I remember from when I was 14 ? And at 15, 16, 17-he describes some of my states of mind so openly and yet in such a self-deluded manner that it feels uncanny. I went through the same religious sequence, precariously balanced between heaven and hell and the world, confronted with the same questions: Will I be saved? And then, the next logical step: If God has saved me, should I become a missionary, to save others? Things have turned out differently. Perhaps that is partly why I find the old document troubling.

I return to it; there is something that worries me about its lack of conclusion. They let him become a missionary, I think to myself. I shrink back from the text in front of me; the venerable board of the mission society in the 1840s sent this young man out to the unmapped parts of Zululand, as a stranger, to live among a group of people who had not asked him to come, and whom he would not be able to accept support from; how did they think that would affect him? This is unbelievable, I think-no wonder he struggled sorely for the rest of his life. Did they not see how this would play out for him? Or did they see, but decide that it was a sacrifice worth making, for the higher good-his happiness was worth sacrificing if he could travel out to convert the heathen? It was all disturbing enough for me to stop reading. I went for a coffee in the canteen instead, $T$ walked past and came over to join me, the cockroaches crawled out of the window. I didn't read the old application again that day but photocopied it and put the copy on my shelf. On the working assumption that anything that throws me is probably important.

One obscure episode from an obscure Tuesday afternoon—one among other similarly obscure episodes from other obscure afternoons - which shows how the precarious relationship between self and other undergoes some peculiar twists for the anthropologist of home. One moment I am engaging with something that seems other, 
that seems strange, only to find that it is suddenly disconcertingly familiar; the next moment I see myself, I see something familiar, only to find that it is something very strange. Unheimlich: the uncanny terror of seeing the border between familiar and unfamiliar, home and un-home, suddenly break down. 'It is enough...', I think, halfremembering an existentialist theology quote: 'enough to make anyone dizzy' (Tillich 1952: 147). It is also enough to push one to the same acute question: 'How can things be this way?'

A while later I returned to the photocopied application and read it a second time. I started underlining a few of the sentences written down by this young man. As I read I became gradually more and more interested in him; I read about his suicide plan during one of the troughs of his religious crisis and how he didn't go through with it because, standing on the pier above his imminent death, he remembered that his mother 'took things to heart, even little things'. I started feeling compassion for him. In my notes from that day there are a few rather more dispassionate, typed sentences: 'I am not quite sure why it affected me so strongly when I read it last time. To me now, it seems interesting. It shows how he dealt with himself, how he used God's word both to shut himself in and to be able to come out of himself. It links this rather crystallized version of pietism with the mission calling; his desire for the heathen to go through the same emotional process as he has been through; this is an interesting way of gaining an insight into the Christian culture he was in. And the mission culture.' While my notes from the first reading have a sense of immediacy and importance about them, these second notes seem almost cold, a bit detached. But they were the start of an important process.

And now I'm reading the application from 1842 for the third time. To answer the question: So why is it interesting to study home? The answer must lie in the combination of the uncanny experience of the first reading - the experience which touches a raw nerve, and the second, more detached reading, and the third and fourth and fifth and sixth-where one slowly starts to examine the event from several different perspectives.

\section{Back to home}

Let me return to the quote about shifts in location:

'the knower's location and life experience are somehow central to the kind of knowledge produced. Yet... a shift of location has been reduced to the idea of going "elsewhere" to look at "another society".' (Gupta and Ferguson 1997: 35)

In sum, shifts in location, and the perspectives of the knower, may be realized through studies 'of' and 'at', as well as 'away from' home. Cockroach moments can happen anywhere. I have been concerned here with the particular cockroaches that breed in the familiar - whether at SOAS or in Stavanger-and how they can provide moments of ethnographic self-awareness and insight that can be used to produce anthropological knowledge. I also want to suggest that the dislocation insights that happen at home throw up interesting questions around the category of home itself, and how this category is used within the anthropological discipline. Is home normal, or is it a site of difference (Gupta and Ferguson 1997: 15)? Is home a safe feeling or does it trigger sentiments that are unheimlich, unhomelike at home? Home is all of the above; ambivalent to the point of being both gratifying and terrifying. Normal, different, safe, 
unheimlich-packed with anthropological insights. Not to mention crawling with cockroaches.

\section{References}

Amit, V. 2000. Introduction: constructing the field. In Constructing the field: ethnographic fieldwork in the contemporary world (ed) V. Amit. London: Routledge.

Des Chene, M. 1997. Locating the past. In Anthropological locations: boundaries and grounds of a field science (eds) A. Gupta \& J. Ferguson. Berkeley: University of California Press.

Freud, S. 1953. The uncanny. In The standard edition of the complete psychological works of Sigmund Freud, XVII. London: Hogarth.

Gupta, A. \& J. Ferguson. 1997. Discipline and practice: 'the field' as site, method, and location in anthropology. In Anthropological locations: boundaries and grounds of a field science (eds) A. Gupta \& J. Ferguson. Berkeley: University of California Press.

Mosse, D. 2005. Cultivating development. London: Pluto Press.

Okely, J. 1996. Own or other culture. London: Routledge.

Pink, S. 2000. 'Informants' who come 'home'. In Constructing the field: ethnographic fieldwork in the contemporary world (ed) V. Amit. London: Routledge.

Tillich, P. 1952. The courage to be. New Haven: Yale University Press.

\section{About the author}

Ingie Hovland is a PhD student in the Department of Anthropology at the School of Oriental and African Studies (SOAS), London. Her PhD research is on the Norwegian Mission Society, focusing on how four individuals who have been engaged in the mission during different time periods - from the 1840s until today-have lived and struggled with the mission idea.

Email: ingiehovland@yahoo.co.uk 